\title{
Maintainability Evaluation of Steam and Gas Turbine Components in a Thermal Power Station
}

\section{Christian Emeka Okafor ${ }^{1}$, Augustine Alexander Atikpakpa ${ }^{2}$, Ugochukwu Chuka Okonkwo, Ekerikevwe Kennedy Irikefe $^{3}$}

\author{
${ }^{1}$ Department of Mechanical Engineering, Nnamdi Azikiwe University, Awka, Nigeria \\ ${ }^{2}$ Department of Mechanical Engineering, Delta State Polytechnic, Otefe-Oghara, Nigeria \\ ${ }^{3}$ Department of Statistic, Delta State Polytechnic, Otefe-Oghara, Nigeria
}

\author{
Email address: \\ ce.okafor@unizik.edu.ng (C. E. Okafor), atikpakpaaugustine1@yahoo.com (A. A. Atikpakpa), \\ cu.okonkwo@unizik.edu.ng (U.C. Okonkwo), kennedyekerikevwe@gmail.com (E. K. Irikefe)
}

\section{To cite this article:}

Christian Emeka Okafor, Augustine Alexander Atikpakpa, Ugochukwu Chuka Okonkwo, Ekerikevwe Kennedy Irikefe. Maintainability Evaluation of Steam and Gas Turbine Components in a Thermal Power Station. American Journal of Mechanical and Industrial Engineering. Vol. 2, No. 2, 2017, pp. 72-80. doi: 10.11648/j.ajmie.20170202.13

Received: November 10, 2016; Accepted: December 27, 2016; Published: January 20, 2017

\begin{abstract}
Maintenance costs have risen steadily over recent years in proportion to total investment in thermal power stations, however lack of regular maintenance can result in serious equipment failure with catastrophic consequences. In general, the Nigerian power generation capability has nosedived to an abysmal level, particularly at the generation stations due to poor maintenance culture. This paper evaluated maintainability of steam and gas turbines components in a thermal power station. Data were obtained from a thermal power station in Nigeria; these raw data were extracted from the operation department, which represents records of plant generation capabilities as well as other inherent daily conditions that will enhance the success of this study. Various maintainability measures were used in analyzing the data, the study implemented log normal distribution considering that most turbines fails due to fatigue and other phenomenon that are caused by ageing or wear resulting in failure rates that increase with time. The estimated mean time to failure of turbine 2 reduced from 35744.5 hours to 33643.8 hours after the use of a condition based preventive maintenance policy. Mean Preventive Maintenance Time (MPMT) for Economizer Inlet non Return Valve and its effect on steam turbine 1 ranges from 77144hrs to 4296hrs for gas turbine 2. The station overall mean maintenance time showed that steam turbine 1 has a maximum hours (77144hrs), while its is minimum for gas turbine2 (4296 hrs). MPMT of sub-equipment is maximum up to $48717 \mathrm{hrs}$ on Gear defect/Hood diaphragm for steam turbine 2; also maximum for the Economizer Inlet non Return Valve, while this was minimum about 48708 hrs for the water pump. For gas turbine 2 MPMT hours for seal leakages and air filters have a maximum value of about 4295.5 hrs, while it is very low on other equipment. The equipment maximum corrective maintenance time (MCMT) of various turbines is higher for steam turbine $2(10.04 \mathrm{hrs})$, while minimum for gas turbine 2 (10.00 hrs). Conclusively, planned maintenance tasks can reduce the number of unplanned or emergency trips of these turbines.
\end{abstract}

Keywords: Maintainability, Steam Turbine, Gas Turbine, Power Station, Lognormal Distribution

\section{Introduction}

In the past, the maintenance practices of Nigerian industries has been learned through experience and rarely examined analytically. However, increased performance requirements have led to complex maintenance needs which necessitates adoption of more engineered decision support for maintenance of equipments. A lot of investment has been channelled to power generation process and automation to enhance the reliability of this systems, this requires adequate maintenance. Maintenance of process instruments and equipment play a major role in the smooth running of such process $[1 ; 2]$. Effective maintenance of turbines are obviously one of the most important aspects of modern thermal power station. Since the dawn of industrialization, people who were experts in maintenance, repairing, and diagnosing machines were entirely invaluable. Maintainability is defined as the probability of performing a successful repair action within a given time. In other words, maintainability measures the ease and speed with which a system can be restored to operational status after a failure occurs. The repair rate is a random variable since it is dependent on the nature of failure, ability to analyze the root cause of failure and expert human resources to carry out the 
repair procedure [3]. Maintainability is the ability of an item to be maintained, whereas maintenance constitutes a series of actions to be taken to restore or retain an item in an effective operational state [4].

The objectives of maintainability components is to isolate and correct defects, identify and repair damaged components without replacing other still working parts, prevent unexpected breakdowns, improve components useful life, enhance components efficiency and reliability. In most cases, maintainability involves learning from the past in order to improve the reliability of systems based on maintenance experience [5].

Zahir [6] developed reliability Models of adequately maintained systems incorporating measures used in maintainability analysis. Desai and Mital [7] evaluated strategies for improving maintainability of products through the adoption of a comprehensive design for maintainability measures. Teodor and Adina [8] studied reliability and maintainability of electric cable machinery utilizing Weibull ++9 software for characterization of functional safety and maintainability. Ding [9] examined product maintainability design method and support tool based on feature model. Sulaiman [10] evaluated the effect of planned preventive maintenance application on the performance of Egbin thermal power station, they used the overall equipment effectiveness model (OEE) approach which comprises of availability rate, performance rate, and quality rate to carry out the work. Adeoye and Bamisaye [11] carried out performance evaluation and analysis of Omotoso pwer plant in Nigeria, Bezerra et al [12] analyzed the feature models maintainability over their evolution process, Jha [13] studied the reliability and maintainability of electrical drives with particular reference to capital intensive heavy coal mining machineries, Zdravko et al [14] examined the evaluation and monitoring of condition of turbo generator on the example of thermal power plant Ugljevik 1x300 MW. Lu [15] undertook maintainability fuzzy evaluation based on maintenance task virtual simulation for aircraft system. Mohamed [16] carried out performance and maintainability evaluation of antispyware system, Isono [17] studied maintainability and repairability for Japan Sodium-Cooled Fast Reactor (JSFR), they identified a number of parts which have difficulty in maintenance and repair in main components of the reactor structure and the primary/secondary main coolant system. Hoffner et al [18] made efforts in creating a balance of cost, reliability, and maintainability for utility-scale PV power plants. Mohebbi [19] proposed maximum maintainability of complex systems via modulation based on DSM and module layout, Tian and Liao [20] examined condition based maintenance optimization for multi-component systems using proportional hazards model,

Kumar [21] reviewed reliability, availability and maintainability analysis of a process industry. Peng and Vayenas [22] in a case studies with an LHD Vehicle carried out maintainability analysis of underground mining Equipment using genetic algorithms. Atikpakpa, [23] employed the exponential and Weibull density models to evaluate the failure and reliability of six turbines as an individual component in a Nigerian thermal plant. Corvaro et al [24] X-rayed the reliability, availability, maintainability of reciprocating compressors API 618. Wu et al [25] carried out risk-based inspection and maintenance in process plants and their practices in Taiwan, they addressed various content of risk-based assessment and maintenance employed in process plants

Obviously, recent research has implemented various models of maintainability for different process equipments, but little research has focused on the steam and gas turbine components in a thermal power station. Studies that have examined maintenance problems in industries have focused almost exclusively on comprehensive design for maintainability measures. However the current study specifically reviewed various distributions for maintainability analysis and adopted log normal distribution considering that most turbines fails due to fatigue and other phenomenon that are caused by ageing or wear resulting in failure rates that increase with time.

\section{Applicable Statistical Distributions in Maintainability Evaluation}

Some of the applicable distributions for maintainability analysis include the normal, lognormal, and exponential distributions [6]. The exponential distribution applies to maintenance tasks and maintenance actions whose completion times are independent of previous maintenance experience [6, 26, 27].

Lognormal distribution applies to most maintenance and repair actions involving subsidiary tasks of unequal frequency and time duration [6, 28, 29]. The normal distribution is mostly useful in relatively straightforward maintenance tasks and repair actions which consistently require a fixed amount of time for its completion [30]. Weibull and gamma distributions are applicable in maintainability analysis depending upon the analysis of the data and the use of "goodness of fit" tests [31.28].

The possibility that the turbine will be repaired in a specified period of time is characterized by maintainability and represented by a lognormal distribution; hence lognormal distribution is commonly used to model the lives of units whose failure modes are of a fatigue-stress nature $[6,32]$. This paper will concentrate on the use of the lognormal distribution, and its use in maintainability analysis.

\section{Materials and Methods}

Data were obtained from a thermal power station in Nigeria. These raw data were extracted from the operation department, which represents records of plant generation capabilities as well as other inherent daily conditions that will enhance the success of this study. From the records obtained, daily, monthly and yearly data of power generated were computed. In addition, during the process of gathering data on this research work, both junior and senior staffs of the technical department of the plant operation unit of the thermal power station were interviewed to get some other relevant information which was of a great assistance to the success of this work. The prescribed procedure include not only the certain manner of actions but it also include 
availability of maintenance resources (spare parts, tools, manuals and labors), scheduling of maintenance, skilled personnel and number of peoples assign for the maintenance. Various researchers including Kusiak and Lee [33]; Dhillon [34] and Ding [9] has previously established the following measures used in maintainability analysis.

A. Mean time to repair (MTTR)

Mean Time To Repair, MTTR, is the actual time it takes to perform corrective maintenance. It is thus a maintenance activity that takes place after a function failure has been discovered. The MTTR is the mean of the distribution of turbine repair time and is estimated from the following equation $[34 ; 33]$.

$$
\operatorname{MTTR}=\frac{\sum_{i=1}^{n} \lambda_{i} M_{i}}{\sum_{i=1}^{n} \lambda_{i}}
$$

Where

$M_{i}=$ The time needed to repair the turbine when component $i$ fail. It also means the maintenance time for preventive maintenance activity $i$.

$\mathrm{n}=$ Number of repaired components in the system

$\lambda_{i}=$ Failure rate of the $i^{t h}$ repairable component in the system

B. Maintenance Function $\left(\mathrm{M}_{(\mathrm{t})}\right)$

In addition to these measures, maintainability functions are used to predict the probability that a turbine repair, starting at time $\mathrm{t}=0$, will be completed in a time $\mathrm{t}$. Mathematical expression of maintainability according to Gupta [35] is

$$
M_{(t)}=1-e^{-(t / M T T R)}
$$

The maintainability density functions of a lognormal random variable $\mathrm{Tr}$ whose logarithm is normally distributed has been proposed by Muralidharan and Syamsundar [36] as follows:

$$
M(t)=\frac{1}{t \sigma \sqrt{2 \pi}} \exp \left[-\frac{1}{2}\left(\frac{\ln (t)-\mu}{\sigma}\right)^{2}\right] \cdot t>0, \sigma>0
$$

The corresponding maintainability function is given by

$$
\begin{gathered}
M(t)=\int_{-\infty}^{t} \frac{1}{x \sigma \sqrt{2 \pi}} \exp \left[-\frac{1}{2}\left(\frac{\ln (x)-\mu}{\sigma}\right)^{2}\right] d x \\
M(t)=\Phi\left(\frac{\ln (x)-\mu}{\sigma}\right), t>0, \sigma>0
\end{gathered}
$$

Where,

$\mathrm{M}(\mathrm{t})=$ Maintainability at time $\mathrm{t}$,

$\Phi=$ Standard normal distribution cumulative function

$\mu=$ Lognormal distribution mean value

$\sigma=$ Lognormal distribution standard deviation

C. The Standard Deviation (SD)

The standard deviation of the lognormal distribution $\left(\boldsymbol{\sigma}_{T}\right)$, as discussed in Kececioglu [37] is expressed as

$$
\sigma_{T}=\sqrt{\left(e^{2 \mu^{\prime}+\sigma^{\prime 2}}\right)\left(e^{\sigma^{\prime 2}}-1\right)}
$$

D. Mean Preventive Maintenance Time (MPMT)

According to Dhillon [34] the objective of the preventive maintenance program is to postpone the point at which the equipment or any of its components wears out or breaks down.

$$
\operatorname{MPMT}=\frac{\sum_{i}^{n} T_{m p i} F_{p t i}}{\sum_{i}^{n} F_{p t i}}
$$

$T_{m p i}$ is the elapsed time for preventive maintenance task $\mathrm{i}$ for $\mathrm{i}=1,2,3 \ldots . . \mathrm{n} . F_{p t i}$ is the frequency of preventive maintenance task $\mathrm{i}$, for $\mathrm{i}=1,2,3, \ldots \mathrm{n}$. $\mathrm{n}$ is the number of preventive maintenance tasks.

E. Overall Mean Maintenance Time (OMMT)

To calculate the Mean Maintenance Time all in all, that is to say the total time of maintenance considering both corrective and preventive maintenance task, $f$ is the frequency of maintenance.

$$
\mathrm{OMMT}=\frac{\lambda \cdot M T T R+f \cdot \mathrm{MPMT}}{\lambda+f}
$$

F. Maximum corrective maintenance time (MCMT)

According to Ding [9], MCMT for lognormal distribution measures the time required to complete all potential repair activities up to a given percentage, often $90^{\text {th }}$ or $95^{\text {th }}$ percentiles.

$$
\mathrm{MCMT}=\operatorname{anilog}\left(T_{m}+k \sigma\right)
$$

Where

$T_{m c m}=$ maximum corrective maintenance time.

$T_{m}=$ mean of the logarithms of the repair times.

$\sigma=$ standard deviation of the logarithms of repair times.

$k=1.28-1.64$ for $90^{\text {th }}$ and $95^{\text {th }}$ percentiles.

G. Mean Maintenance Down Time (MMDT)

This is the total time needed either to restore equipment to a specified performance level to maintain it at that level of performance. Thus, it includes active corrective and preventive maintenance times, administrative and logistic delay times.

$$
\mathrm{MMDT}=\mathrm{OMMT}+T_{a d}+T_{l d}
$$

$T_{a d}$ is the admnistrative delay time. Asssumed to be $600 \mathrm{hrs}$ and $T_{l d}$ is the logistic delay time assumed to be $500 \mathrm{hrs}$.

H. Mean time to failure (MTTF):

The mean of the lognormal distribution $(\mu)$, is discussed in Kececioglu [37].

$$
\mu=e^{\mu^{\prime}+\frac{1}{2} \sigma^{\prime 2}}
$$

Where,

$$
\mu^{\prime}=\frac{\sum \lambda}{n} \sigma^{\prime 2}=\sqrt{\frac{\sum(x-\bar{x})^{2}}{n}}
$$

\section{Results and Discussion}

The thermal station has a very low maintenance structured for most of the units assessed in this study and as such these cannot guarantee maximum and efficient equipment performance. Gas turbine 01 and 02 was most affected while for the steam turbines maintenance is also very low for this station. For the gas turbines, equipment utilization remains nil for most of the turbines, which indicates the slower pace 
in maintenance culture in the station. Table 1 and 2 showed the lognormal distribution parameters for maintainability of steam and gas turbines. These were computed using equation 4-10.

Table 1. Lognormal distribution parameters for maintainability of steam and gas turbines.

\begin{tabular}{lll}
\hline \multirow{2}{*}{ System } & \multicolumn{2}{l}{ Lognormal Distribution Parameters } \\
\cline { 2 - 3 } & Mean Value $(\boldsymbol{\mu})$ & Standard Deviation $(\boldsymbol{\delta})$ \\
\hline Steam turbine 01 & 1.0003 & 0.00013 \\
Steam turbine 02 & 1.0002 & 0.00016 \\
Steam turbine 06 & 1.0005 & 0.00011 \\
Gas turbine 01 & 1.0001 & 0.00047 \\
Gas turbine 02 & 1.00006 & 0.000084 \\
\hline
\end{tabular}

Table 2. Lognormal distribution for maintainability of steam and gas turbines.

\begin{tabular}{|c|c|c|c|c|c|c|c|}
\hline Year & & & 2003 & 2004 & 2005 & 2006 & 2007 \\
\hline \multirow{9}{*}{ Maintainability $M(t) \& \beta_{t}$} & \multirow{2}{*}{ ST01 } & $M(t)$ & 0.16 & 0.16 & 0.15 & 0.18 & 0.16 \\
\hline & & $\beta_{\mathrm{t}}$ & 7920 & 7776 & 8544 & 8616 & 1824 \\
\hline & \multirow{2}{*}{ ST02 } & $M(t)$ & 0.17 & 0.15 & 0.15 & 0.18 & 0.18 \\
\hline & & $\beta_{\mathrm{t}}$ & 7440 & 8016 & 8424 & 7800 & 8448 \\
\hline & \multirow{2}{*}{ ST06 } & $M(t)$ & 0.24 & 0.21 & 0.22 & 0.25 & 0.24 \\
\hline & & $\beta_{\mathrm{t}}$ & 1872 & 1560 & 1150 & 1368 & 528 \\
\hline & GT01 & $M(t)$ & 0.17 & 0.15 & - & - & - \\
\hline & \multirow{2}{*}{ GT02 } & $M(t)$ & 0.27 & 0.19 & - & - & \\
\hline & & $\beta_{\mathrm{t}}$ & 336 & 3072 & - & - & - \\
\hline \multirow[t]{5}{*}{ Year } & & & 2008 & 2009 & 2010 & 2011 & 2012 \\
\hline & \multirow{2}{*}{ ST01 } & $M(t)$ & 0.16 & 0.16 & 0.18 & 0.16 & 0.16 \\
\hline & & $\beta_{\mathrm{t}}$ & 8112 & 8424 & 8400 & 8328 & 8400 \\
\hline & \multirow{2}{*}{ ST02 } & $M(t)$ & -- & -- & -- & 0.15 & -- \\
\hline & & $\beta_{\mathrm{t}}$ & -- & -- & -- & 8592 & -- \\
\hline \multirow{5}{*}{ Maintainability $M(t) \& \beta_{t}$} & ST06 & $\beta_{\mathrm{t}}$ & 72 & 768 & 768 & - & 840 \\
\hline & \multirow{2}{*}{ GT01 } & $M(t)$ & - & - & - & - & - \\
\hline & & $\beta_{\mathrm{t}}$ & - & - & - & - & - \\
\hline & \multirow{2}{*}{ GT02 } & $M(t)$ & 0.24 & - & - & - & - \\
\hline & & $\beta_{\mathrm{t}}$ & 888 & - & - & - & - \\
\hline
\end{tabular}

Table 3-7 highlight the analysis of the turbines using some equipment maintainability parameters, such as equipment Mean Preventive Maintenance Time (MPMT), Mean Maintenance Down Time (MMDT), Maximum corrective maintenance time (MCMT), Overall Mean Maintenance Time (OMMT), the mean and standard deviation on the repair status for Maintainability of equipment. Based on analysis, MPMT for steam turbine 1 is as high as $77144 \mathrm{hrs}$ and as low as $4296 \mathrm{hrs}$ in gas turbine 2. The overall mean maintenance time for steam turbine 1 is maximum about $77141 \mathrm{hrs}$ in Economizer Inlet non Return Valve and air filters, while its is minimum $77123 \mathrm{hrs}$ for seal leakages. For steam turbine 2 MPMT is maximum to about 48717 in Gear/Hood diaphragm and Economizer Inlet non Return Valve, while its is minimum 48708 in Water Pump. For gas turbine 2 Mean Preventive Maintenance Time is maximum about 4295.5 in seal leakages and air filters, while it's is minimum on other equipments. The standard deviation of mean repair time of equipment is higher in steam turbine 2 and lower in gas turbine 2. The equipment maximum corrective maintenance time MCMT is higher to about 10.04, for steam turbine 2 but and minimum value of 10.00 for gas turbine 2 .

Table 3. Repair time of steam turbines 01 (hrs).

\begin{tabular}{|c|c|c|c|c|c|c|c|}
\hline system & $\begin{array}{l}\text { Field } \\
\text { breaker }\end{array}$ & $\begin{array}{l}\text { Boiler Field } \\
\text { pump }\end{array}$ & $\begin{array}{l}\text { Gear/Hood } \\
\text { diaphragm }\end{array}$ & Water Pump & $\begin{array}{l}\text { Econo. Inlet non } \\
\text { Return Valve } \\
\end{array}$ & Leakage seal & Air Filters \\
\hline ST01 & 2 & 2 & 2 & - & 1 & 7 & 1 \\
\hline MTTR & 252 & 64.8 & 120 & & 120 & 113.14 & 24 \\
\hline Actual time for repair $(\mathrm{T})$ & 504 & 648 & 240 & & 120 & 792 & 24 \\
\hline T/MTTR & 2 & 1.13 & 2 & - & 1 & 7 & 1 \\
\hline M (t) at MTTR (hrs) & 0.865 & 0.675 & 0.865 & - & 0.632 & 0.999 & 0.632 \\
\hline $\mathrm{M}(\mathrm{t})$ at TTR $(\mathrm{min})$ & 51.88 & 40.52 & & - & 37.93 & 59.94 & 37.94 \\
\hline OMMT & 77137.5 & 77140.8 & 77138 & - & 77141 & 77123 & 77141 \\
\hline MMDT & 78237.5 & 78240.8 & 78238 & - & 78241 & 78223 & 78241 \\
\hline MTTF & 3942 & 799.2 & 4200 & - & 8520 & 1218.1 & 8616 \\
\hline
\end{tabular}


Table 4. Repair Time of Steam Turbines 02 (Hrs).

\begin{tabular}{|c|c|c|c|c|c|c|c|}
\hline $\begin{array}{ll}\text { system } & \text { Components } \\
\end{array}$ & $\begin{array}{l}\text { Field } \\
\text { breaker }\end{array}$ & $\begin{array}{l}\text { Boiler Field } \\
\text { pump }\end{array}$ & $\begin{array}{l}\text { Gear/Hood } \\
\text { diaphragm }\end{array}$ & Water Pump & $\begin{array}{l}\text { Econo. Inlet non } \\
\text { Return Valve }\end{array}$ & Leakage seal & Air Filters \\
\hline ST02 & - & 3 & 1 & 4 & 1 & 4 & - \\
\hline MTTR & - & 336 & 957 & 234 & 336 & 144 & - \\
\hline Actual time for repair $(\mathrm{T})$ & - & 336 & 957 & 936 & 336 & 576 & - \\
\hline T/MTTR & - & 1 & 1 & 4 & 1 & 4 & - \\
\hline M (t) at MTTR (hrs) & - & 0.865 & 0.632 & 0.982 & 0.632 & 0.982 & - \\
\hline $\mathrm{M}(\mathrm{t})$ at TTR $(\mathrm{min})$ & - & 51.88 & 37.92 & 58.9 & 37.92 & 58.9 & - \\
\hline OMMT & - & 48710 & 48717 & 48708 & 48717 & 48709 & - \\
\hline MMDT & - & 49817 & 49817 & 49808 & 49817 & 49809 & - \\
\hline MTTF & - & 2824 & 7683 & 2101.5 & 8304 & 2124 & - \\
\hline
\end{tabular}

Table 5. Repair time of steam turbines 06 (hrs).

\begin{tabular}{|c|c|c|c|c|c|c|c|}
\hline $\begin{array}{ll}\text { system } & \text { Components } \\
\end{array}$ & $\begin{array}{l}\text { Field } \\
\text { breaker }\end{array}$ & $\begin{array}{l}\text { Boiler Field } \\
\text { pump }\end{array}$ & $\begin{array}{l}\text { Gear/Hood } \\
\text { diaphragm }\end{array}$ & $\begin{array}{l}\text { Water } \\
\text { Pump }\end{array}$ & $\begin{array}{l}\text { Econo. Inlet non } \\
\text { Return Valve } \\
\end{array}$ & Leakage seal & Air Filters \\
\hline ST06 & - & 5 & 4 & 3 & - & 14 & 4 \\
\hline MTTR & - & 2976 & 132 & 112 & - & 183.4 & 354 \\
\hline Actual time for repair $(\mathrm{T})$ & - & 1488 & 528 & 336 & - & 2568 & 1416 \\
\hline T/MTTR & - & 0.5 & 4 & 3 & - & 14 & 4 \\
\hline M (t) at MTTR (hrs) & - & 0.394 & 0.982 & 0.950 & - & 0.999 & 0.982 \\
\hline $\mathrm{M}(\mathrm{t})$ at TTR $(\mathrm{min})$ & - & 23.6 & 58.9 & 57.01 & - & 60 & 58.9 \\
\hline OMMT & - & 8924.8 & 8922.6 & 8925 & - & 8919.2 & 8924.6 \\
\hline MMDT & - & 10024.8 & 10022.6 & 10025 & - & 10019.2 & 10024.6 \\
\hline MTTF & - & 1668.5 & 2127 & 2843 & - & 604 & 2071.5 \\
\hline
\end{tabular}

Table 6. Repair Time Of Gas Turbines 01 (Hrs).

\begin{tabular}{|c|c|c|c|c|c|c|c|}
\hline system $\quad$ Components & $\begin{array}{l}\text { Field } \\
\text { breaker }\end{array}$ & $\begin{array}{l}\text { Boiler Field } \\
\text { pump }\end{array}$ & $\begin{array}{l}\text { Gear/Hood } \\
\text { diaphragm }\end{array}$ & $\begin{array}{l}\text { Water } \\
\text { Pump }\end{array}$ & $\begin{array}{l}\text { Econo. Inlet non } \\
\text { Return Valve }\end{array}$ & Leakage seal & Air Filters \\
\hline GT01 & - & - & - & - & - & - & 9 \\
\hline MTTR & - & - & - & - & - & - & 413.7 \\
\hline Actual time for repair (T) & - & - & - & - & - & - & 3724 \\
\hline T/MTTR & - & - & - & - & - & - & 9 \\
\hline M (t) at MTTR (hrs) & - & - & - & - & - & - & 0.999 \\
\hline $\mathrm{M}(\mathrm{t})$ at TTR $(\mathrm{min})$ & - & - & - & - & - & - & 60 \\
\hline OMMT & - & - & - & - & - & - & 5676.2 \\
\hline MMDT & - & - & - & - & - & - & 6776.2 \\
\hline MTTF & - & - & - & - & - & - & 914.02 \\
\hline
\end{tabular}

Table 7. Repair Time Of Gas Turbines 02 (Hrs).

\begin{tabular}{|c|c|c|c|c|c|c|c|}
\hline $\begin{array}{ll}\text { system } & \text { Components } \\
\end{array}$ & $\begin{array}{l}\text { Field } \\
\text { breaker }\end{array}$ & $\begin{array}{l}\text { Boiler Field } \\
\text { pump }\end{array}$ & $\begin{array}{l}\text { Gear/Hood } \\
\text { diaphragm }\end{array}$ & Water Pump & $\begin{array}{l}\text { Econo. Inlet non } \\
\text { Return Valve } \\
\end{array}$ & Leakage seal & Air Filters \\
\hline GT02 & - & - & - & - & - & 1 & 2 \\
\hline MTTR & - & - & - & - & - & 96 & 1944 \\
\hline Actual time for repair $(\mathrm{T})$ & - & - & - & - & - & 96 & 3888 \\
\hline T/MTTR & - & - & - & - & - & 1 & 2 \\
\hline M (t) at MTTR (hrs) & - & - & - & - & - & 0.632 & 0.865 \\
\hline$M(t)$ at TTR $(\min )$ & - & - & - & - & - & 37.93 & 51.88 \\
\hline OMMT & - & - & - & - & - & 4295.5 & 4295.3 \\
\hline MMDT & - & - & - & - & - & 5395.5 & 5395.3 \\
\hline MTTF & - & - & - & - & - & 8448 & 1404 \\
\hline
\end{tabular}

Table 8. Mean Preventive Maintenance Time (Mpmt) And Maximum Corrective Maintenance Time (Mcmt) For Gas And Steam Turbines.

\begin{tabular}{llcccc}
\hline SYSTEM & ST01 & ST02 & ST06 & GT01 & GT02 \\
\hline MPMT (hrs) & 77144 & 48720 & 8926 & 5682 & 4296 \\
MCMT (hrs) & 10.1 & 10.01 & 10.04 & 10.01 & 10.00 \\
\hline
\end{tabular}

The lognormal distribution of equipment maintainability on figure 1 and 2 showed that maintainability of equipment on steam turbine 2 has improved efficient plant performance due to conditional maintenance, which indicates that the failure of the steam turbine 2 is reduced. The planned maintenance tasks have reduced the number of unplanned or emergency trips of this turbine. The availability of steam turbine 2 has increased in one operational year which is very close to the turbine 1 . 


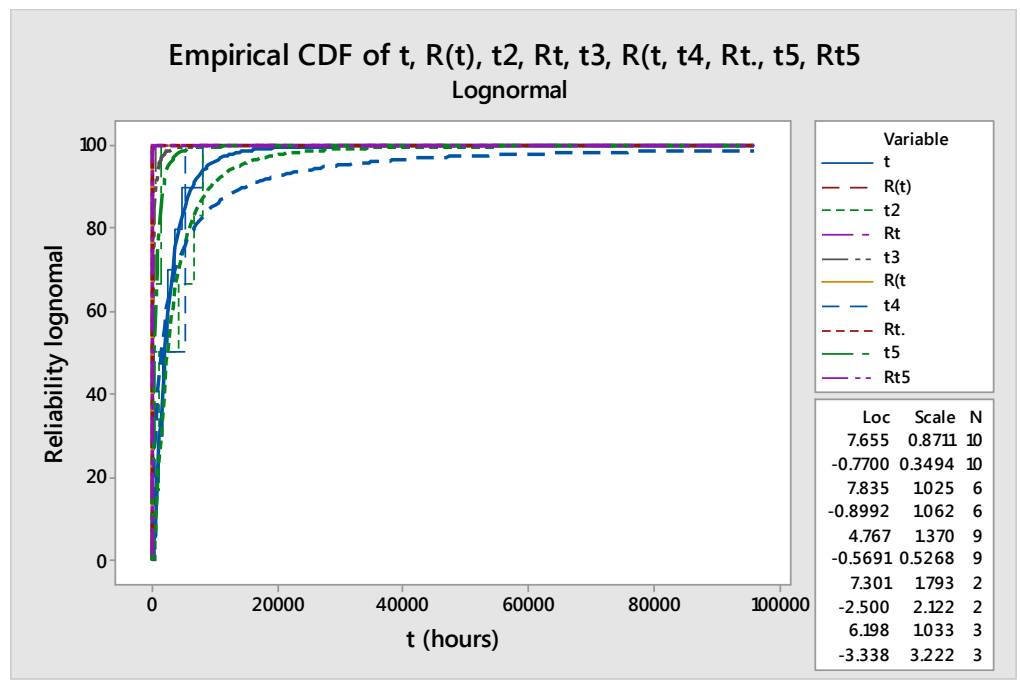

Figure 1. Lognormal Reliability of gas and steam turbines.

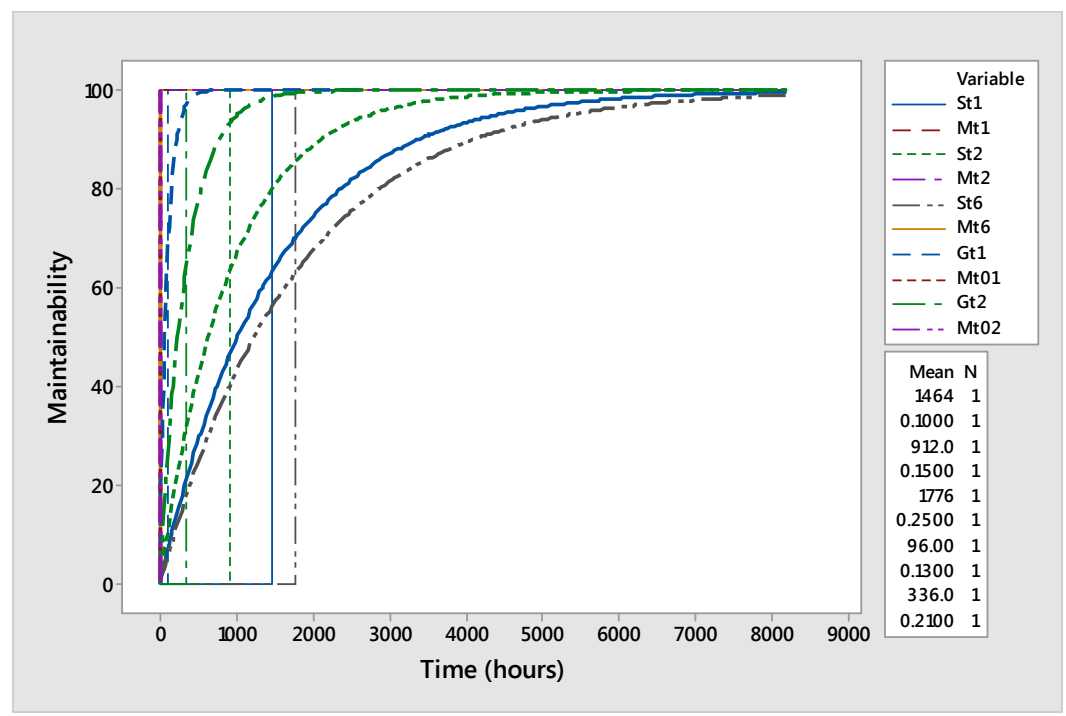

Figure 2. Lognormal Maintainability of gas and steam turbines.

From figure 3-7, each curve compressed on both axes. The vertical axis showed the density of stretchiness of the reliability of both turbines while the horizontal axis showed the minimum life of turbine or the aging condition in hours. The total time of maintenance considering both corrective and preventive maintenance task is in the range of 4295.3-77141 hrs.

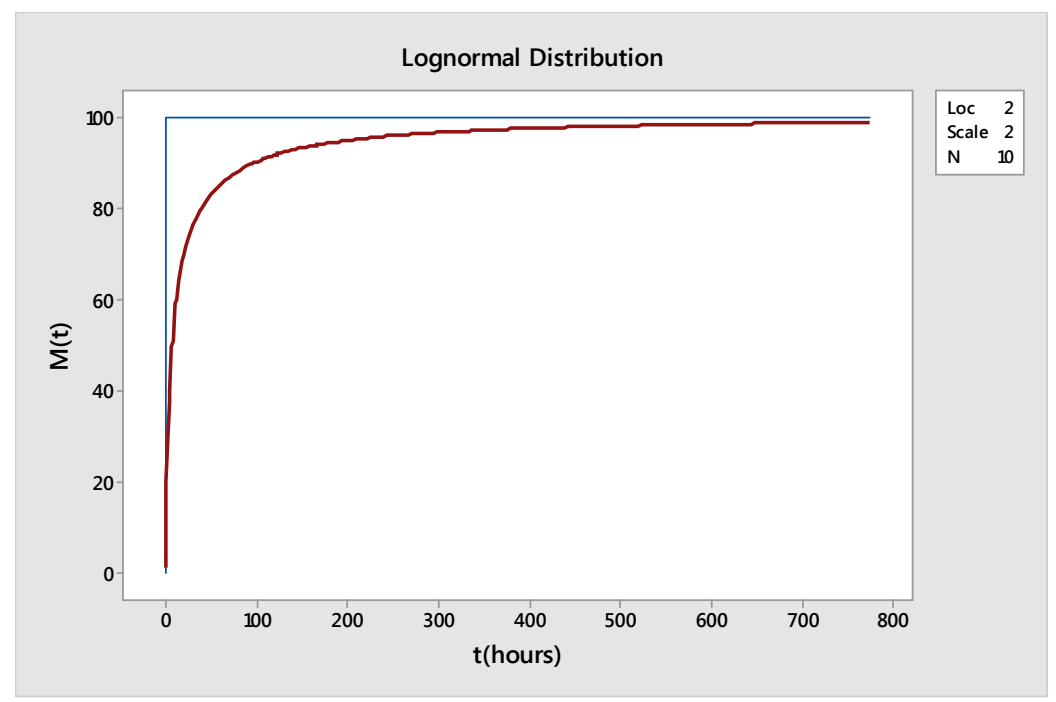

Figure 3. Lognormal Maintainability of ST01 turbines. 


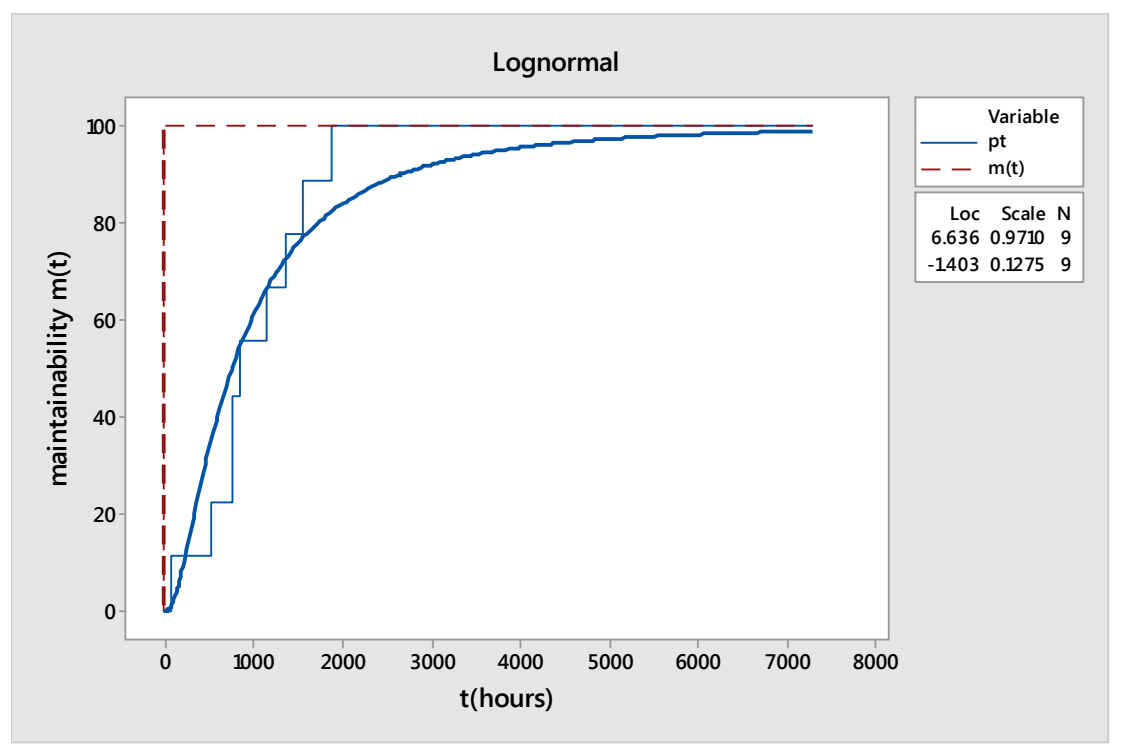

Figure 4. Lognormal Maintainability of ST02 turbines.

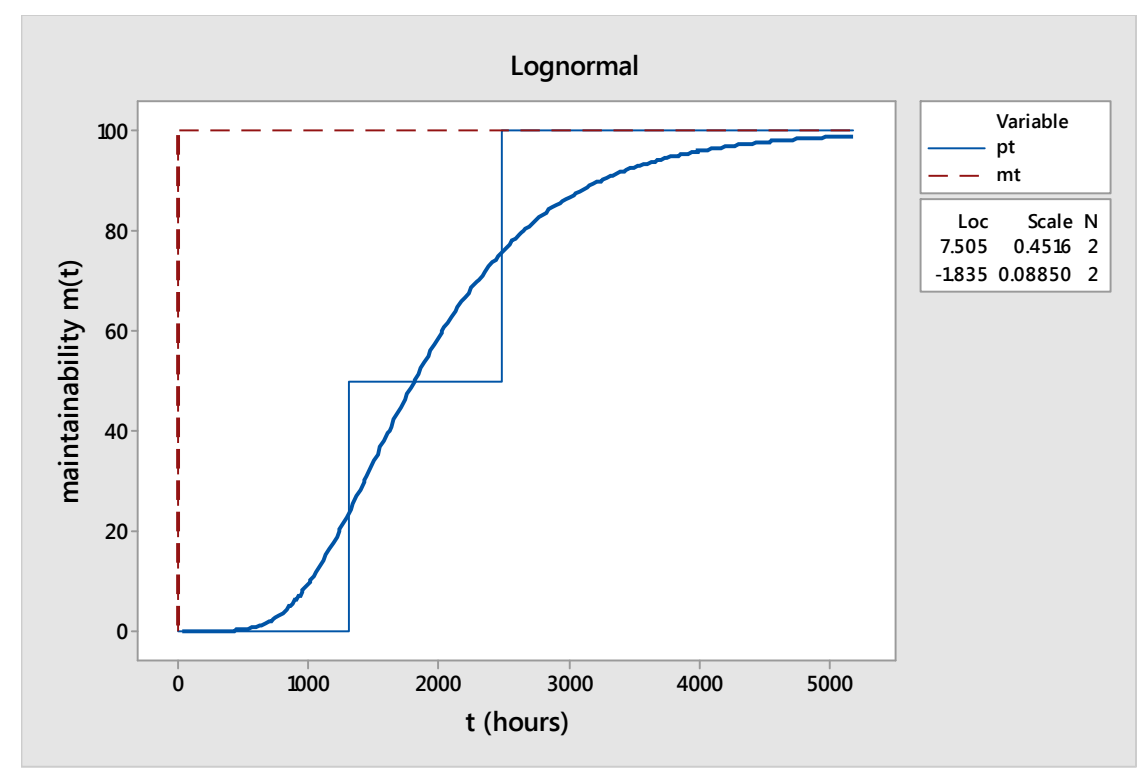

Figure 5. Maintainability of GT01 turbines.

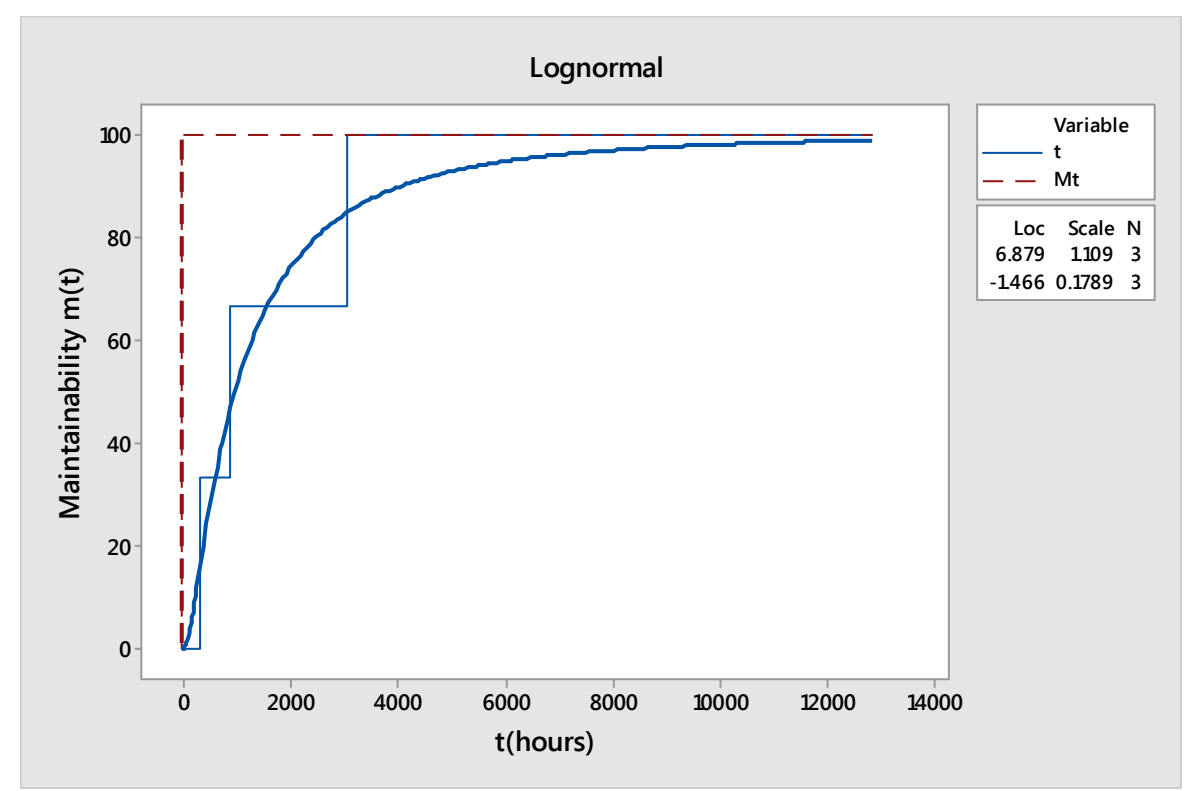

Figure 6. Maintainability of GT02 turbines. 


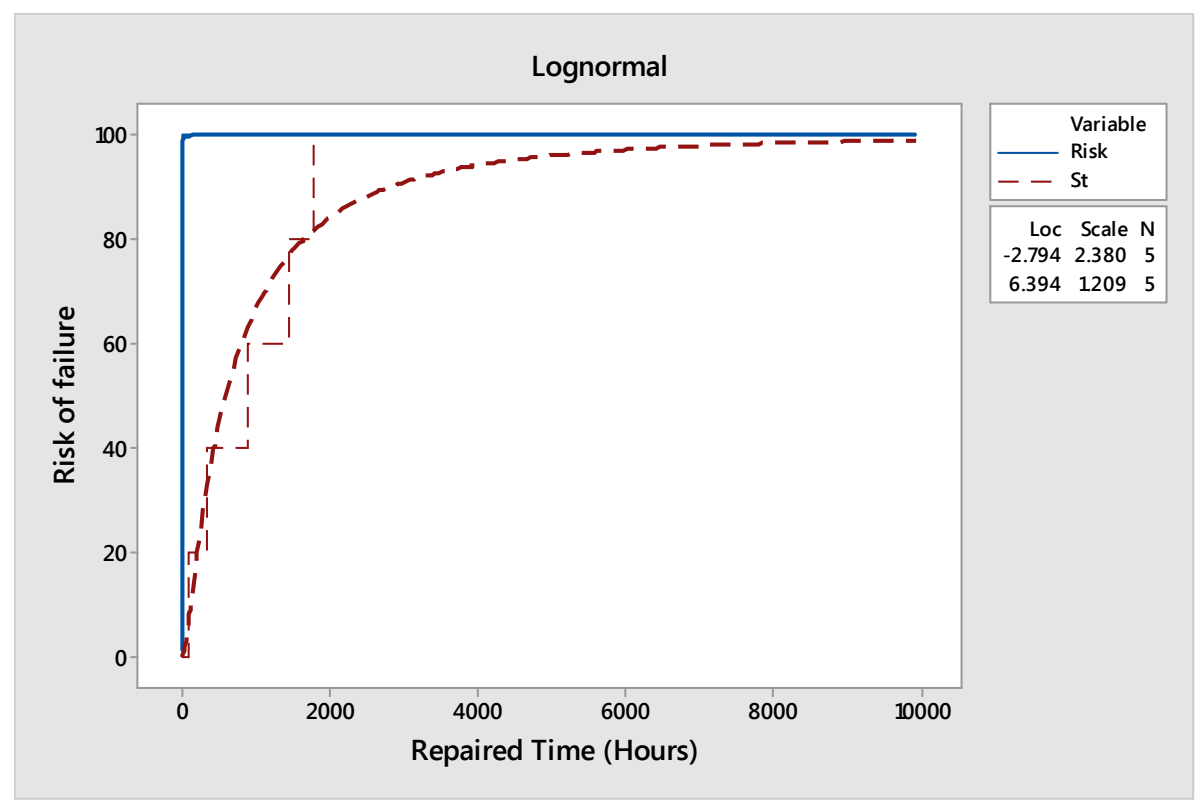

Figure 7. Risk of failure of gas and steam turbines.

The effect of failure caused by leakages along the gas supply line and the failure of boiler feed pump on steam turbine 01 and 02 was high and this subsequently affects their efficiency in power generation. Other inherent problems was the issue of cracked; caused by gear defect \& hood diaphragm and blockage incurred by as a result of dirt on the air filter.

\section{Conclusion}

In this study, various measures used in maintainability analysis were adopted in evaluation of steam and gas turbines components in a thermal power station. It became obvious that reliability of equipment depends on prompt maintenance of equipment; however, when the interval between first maintenance and sub-time of system maintenance becomes farther the reliability figure dropped from unity to zero. Therefore, one of the important factor that is very relevant in the performance of thermal power station is maintainability.

Out of all the sub systems studied, ST01 has the highest preventive maintenance time of $77144 \mathrm{hrs}$ which represents the point at which the turbine or any of its components wears out or breaks down. The total time of maintenance considering both corrective and preventive maintenance task is in the range of 4295.3-77141 hrs. However, average of $10 \mathrm{hrs}$ is required to complete all potential repair activities in the turbine subsystems up to 95th percentiles. On the whole, the total time needed either to restore the turbines to a specified performance level or to maintain it at that level of performance ranges from 78241 - $5395.3 \mathrm{hrs}$. Conclusively, Mean time to repair (MTTR), Mean Preventive Maintenance Time (MPMT), Median Corrective Maintenance Time (MCMT), Overall Mean Maintenance Time (OMMT), Maximum corrective maintenance time (MCMT), Mean Maintenance Down Time (MMDT) and Mean time to failure (MTTF) has been effectively applied in maintainability analysis.

\section{References}

[1] Raje D. V, Olaniya, R. S., Wakhare, P. D and Deshpande A. W. Availability assessment of two unit stand-by pumping system. Reliability Engineering and System safety. 2000. 68: 269-274.

[2] Gupta, S. Tewari, P. C. and Sharma A. K. Reliability and availability analysis of the ash handling unit of a steam thermal power plant. South African Journal of Industrial Engineering. 2009. 20 (1): 147-158.

[3] Shikha J. Study of industrial systems using supplementary variable technique. Master of Science these. School of Mathematics and Computer Applications (SMCA), Thapar University, Patiala. 2012.

[4] Subramani A and Dewhurst, P. Efficient design for service considerations. Manufacturing Review. 1993.6 (1): 40-47.

[5] Nahlah M. A. M. N. Measuring Maintainability Index of a Software Depending on Line of Code Only. IOSR Journal of Computer Engineering (IOSR-JCE). 2014. 16 (2): 64-69.

[6] Zahir A. H. H. Reliability Models of Maintained Systems. Journal of Babylon University/Pure and Applied Sciences. 2013. $6(21)$.

[7] Desai A and Mital A. Improving maintainability of products through the adoption of a comprehensive design for maintainability method. International Journal of Industrial Engineering, 2010. 17 (2): 103-114.

[8] Teodor V. and Adina B. Rreliability and maintainability of electric cable machinery. Annals of Faculty Engineering Hunedoara- International Journal of Engineering.Tome XIV Fascicule 2. 2016.

[9] Ding Y. Product Maintainability Design Method and Support Tool Based on Feature Model. J. Software Engineering \& Applications. 2009. 2: 165-172.

[10] Sulaiman, M. A. Effect of Planned Preventive Maintenance Application on the Performance of Egbin Thermal Power Station. Journal of Energy Technologies and Policy. 2015. 5 (1): $48-52$. 
[11] Adeoye OS, Bamisaye AJ (2016) Performance Evaluation and Analysis of Omotoso Power Plant 2016 in Nigeria. Innov Ener Res 5: 134. doi: 10.4172/ier.1000134.

[12] Bezerra CI, Monteiro JM, Andrade R, Rocha LS. Analyzing the Feature Models Maintainability over their Evolution Process: An Exploratory Study. InProceedings of the Tenth International Workshop on Variability Modelling of Softwareintensive Systems 2016 Jan 27 (pp. 17-24). ACM.

[13] Jha, Mrs Rekha, F. Ansari, and U. K. Dey. reliability and maintainability studies on electrical drives with particular reference to capital intensive heavy coal mining machineries"International Journal of Engineering Research \& Management Technology. 20163 (4).

[14] Zdravko N. Milovanovic, Aleksandar N. Milasinovic, Darko M. Knezevic, Jovan B. Skundric, Svetlana R. DumonjicMilovanovic, Evaluation and Monitoring of Condition of Turbo Generator on the Example of Thermal Power Plant Ugljevik 1x300 MW, American Journal of Mechanical and Industrial Engineering. Vol. 1, No. 3, 2016, pp. 50-57. doi: 10.11648/j.ajmie.20160103.13.

[15] Lu Z, Zhou J, Li N. Maintainability fuzzy evaluation based on maintenance task virtual simulation for aircraft system. Eksploatacja i Niezawodność. 2015; 17 (4).

[16] Mohamed Adel Sheta, Mohamed Zaki, Kamel Abd El Salam El Hadad and Aboelseoud H M.. Performance and Maintainability Evaluation of Anti-Spyware System. International Journal of Computer Applications 150 (4): 3139, September 2016. BibTeX.

[17] Isono K, Kubo S, Chikazawa Y, Dozaki K, Oya T, Yui M. Studies on Maintainability and Repairability for Japan Sodium-Cooled Fast Reactor (JSFR). In2014 22nd International Conference on Nuclear Engineering 2014 Jul 7 (pp. V003T05A007-V003T05A007). American Society of Mechanical Engineers.

[18] Hoffner J, Lyell K, Jackson J, Stibrich S, Whittier J, Campbell R, Krick D, Dart B. Creating a balance of cost, reliability, and maintainability for utility-scale PV power plants. In2013 IEEE 39th Photovoltaic Specialists Conference (PVSC) 2013 Jun 16 (pp. 2373-2375). IEEE.

[19] Mohebbi B, Khayambashi B, Cheshmberah M. Maximum Maintainability of Complex Systems via Modulation Based on DSM and Module Layout Case Study: Laser Range Finder. International Journal of Engineering Science (2008-4870). 2015 Sep 15; 26 (4).

[20] Tian Z. and Liao H. Condition based maintenance optimization for multi-component systems using proportional hazards model, Reliability Engineering and System Safety 96 (2011) pp 581-589.

[21] Kumar S. Reliability, availability and maintainability analysis of a process industry: a state of art review. International Journal of Mathematical Sciences, Technology and Humanities 117 (2014) 1253-1267.

[22] Peng S, Vayenas N. Maintainability Analysis of
Underground Mining Equipment Using Genetic Algorithms: Case Studies with an LHD Vehicle. Journal of Mining. 2014 Feb 19; 2014.

[23] Atikpakpa, A. A., Okafor, C. E. \& Okonkwo, U. C. Failure and reliability evaluation of turbines used in Nigerian thermal plant. Journal of Science, Technology and Environment Informatics, 04, no. 01 (2016): 280-292. DOI: $10.18801 /$ jstei.040116.31.

[24] F. Corvaro, G. Giacchetta, B. Marchetti, M. Recanati, Reliability, Availability, Maintainability (RAM) study, on reciprocating compressors API 618, Petroleum (2016), doi: 10.1016/ j.petlm.2016.09.002.

[25] Wu WF, Lin SR, You JS. Risk-based inspection and maintenance in process plants and their practices in Taiwan. Journal of the Chinese Institute of Engineers. 2016 Mar 18: 1-2.

[26] Govil A. K., Reliability Engineering, TaTaMc - Graw Hill publishing company Ltd., New Delhi, India. 1983.

[27] Srinath L. S. Concepts in Reliability Engineering "East -West press private Ltd. 1985.

[28] Klaas B. and Jack C. L. System Reliability Concepts and Applications", VSSD, ISBN 90-71301-68-0, Netherlands. http://www.vssd.nl/hlf/e003.htm. 2006.

[29] Samanta B., Sarkar B., Mukherjee S. K. Reliability modelling and performance analyses of an LHD system in mining. Journal of the South African Institute of Mining and Metallurgy. 2004. 1-8.

[30] Rohit P., Satyadhar J., Parag P. and Sumant K. Modeling And Reliability Analysis Of Cnt And Mems Based Wireless Sensor Network. Journal of Mathematics and Technology: 2010. 2078-0257.

[31] Tang Y. Extended Weibull Distributions In Reliability Engineering, A Thesis, National University Of Singapore. 2004.

[32] Dewangan, D. N., Jha, M. K., and Banjare Y. P. Reliability Investigation of Steam Turbine Used In Thermal Power Plant. International Journal of Innovative Research in Science, Engineering and Technology. 2014. 3 (7): 14915-14923.

[33] Kusiak A and Lee G. H. Design of Parts and Manufacturing Systems for Reliability and Maintainability. International Journal of Advanced Manufacturing Technology. 1997. 13: 67-76.

[34] Dhillon B. and Reiche, H. Reliability and Maintainability Management, Van Nostrand Reinhold, New York. 1985.

[35] Gupta A. K. Reliability, Maintenance and Safety Engineering, ISBN- 978- 81-318-0521-3. 2009.

[36] Muralidharan, K. and Syamsundar A. Statistical methods for quality, reliability and maintainability. PHI Learning Pvt. Ltd. India. 2012.

[37] Kececioglu, D. Reliability Engineering Handbook, Prentice Hall, Inc., Englewood Cliffs, New Jersey, Vol. 1. 1991. 